\title{
Biografia e historia magistra vitae: sobre a exemplaridade das vidas ilustres no Brasil oitocentista
}

Maria da Gloria de Oliveira*

Resumo: $\mathrm{O}$ artigo discute as relações entre escrita biográfica e historiografia, analisando a noção de exemplaridade subjacente às narrativas das vidas dos brasileiros ilustres, publicadas na Revista do Instituto Histórico e Geográfico Brasileiro, no século XIX. No contexto letrado do Brasil imperial, é possível identificar duas modulações significativas nas formas da biografia: a primeira orientada por um sentido moralizante, encomiástico e memorialístico explícito; a segunda, dotada da ambição de fornecer chaves heurísticas de acesso à apreensão e representação dos quadros gerais do passado. $\mathrm{O}$ argumento central é o de que as aproximações entre biografia e história não se estabeleceram por uma única via, mas foram marcadas por tais modulações e submetidas às demandas gerais de configurações da experiência do tempo.

Palavras-chave: Biografia. Historia Magistra Vitae. Historiografia.

Na medida em que a história dos fatos se mistura com a dos homens, o biógrafo deve, tanto quanto o historiador, escavar o seu objeto, elevar-se naturalmente à grandeza de seus tipos, descer sem esforço até as particularidades individuais e semear os ensinamentos e o pensamento na tessitura das suas narrativas. (tradução nossa)

Charles Noidier

"Doutora em História Social (UFRJ), professora de Teoria da História e Historiografia do Departamento de História e Relações Internacionais da Universidade Federal Rural do Rio de Janeiro (UFRRJ). Projeto de pesquisa financiado pelo CNPq e FAPERJ. E-mail: mgloriaprof@gmail.com

Anos 90, Porto Alegre, v. 22, n. 42, p. 273-294, dez. 2015 


\section{Introdução}

Em dezembro de 1897, no prefácio ao primeiro tomo de $U m$ Estadista do Império, Joaquim Nabuco discorreu sobre os motivos que o impeliram a escrever a biografia de seu pai, o magistrado, senador e prócer do Segundo Reinado, José Thomaz Nabuco de Araújo. A motivação mais imediata da obra estava na existência de uma volumosa coleção de papéis e documentos que, diligentemente acumulados por cerca de quarenta anos de atividade política, constituíam a biblioteca do senador. Nabuco se declarava movido pelo desejo de impedir que o arquivo paterno tivesse o destino do legado de quase todos os homens públicos do país. Em suas palavras, "[...] foi o receio de que, se eu mesmo o não fizesse, nunca fosse utilisada essa para mim preciosa colecção que me decidiu a emprehender a obra" (NABUCO, 1897, p. vi). Não podia manusear tais documentos “[...] sem sentir n'esses papeis a presença de seu espírito, sem comprehender que elles eram os fragmentos de sua vida, que ella devia achar-se alli inteira, completa para quem a pudesse reconstruir [...]" (Ibid., p. v). ${ }^{1}$

O trabalho prévio de seleção e ordenação do vasto acervo documental tivera início entre os anos de 1893 e 1894, no contexto da Revolta da Armada, quando Nabuco dizia ouvir o som do "duello da artilharia do mar e da terra", vindo da baía da Guanabara, em meio à intensa polêmica política sobre a experiência monárquica e o advento da República.

Escrevendo a vida do ultimo senador Nabuco de Araujo, não dou senão uma espécie de vista lateral da sua época. A figura central do segundo reinado é o proprio Imperador, e só quem lhe escrevesse a Vida e a illustrasse com os documentos que elle deve ter deixado, poderia pôr em fóco, em seu ponto de convergencia, a Grande Era Brazileira, a qual lhe pertence. Só d'esse modo se poderia collocar cada um dos estadistas que o cercaram no seu respectivo plano e dar-lhe as suas proporções reaes. A presente Vida é apenas uma contribuição para a historia do reinado de D. Pedro II, um esboço parcial para ser convenientemente reduzido e 
ajustado á perspectiva do quadro, quando se tenha feito egual trabalho a respeito das outras figuras que o hão de compôr. As proporções dadas n'este livro á figura de Nabuco, posso dizel-o sinceramente, não são devidas a nenhum desejo de engrandecel-o á custa dos seus contemporaneos, mas ao facto de ser a biographia d'elle que eu escrevia, aos numerosos documentos que tive para documental-a, e também á circumstancia, que lastimo, de não se ter ainda escripto na mesma escala a vida dos outros homens de Estado. (Ibid., p. vii, grifos meus)

Não por acaso, a recepção e a vasta fortuna crítica acumulada em torno de Um Estadista do Império não fizeram senão demonstrar que as intenções do autor, explicitadas na passagem transcrita anteriormente e no subtítulo do livro - Nabuco de Araújo: sua vida, suas opiniões, sua época - foram muito bem-sucedidas. Desde a sua primeira publicação, passou a ser considerada uma obra que ultrapassava os limites de uma biografia inspirada pelo dever memorialístico. Essa foi a opinião de Machado de Assis que, ao resenhar o livro, notou que Joaquim Nabuco narrava a vida do pai "[...] não à maneira seca das biografias de almanaque, mas pelo estilo dos ensaios ingleses" (ASSIS apud ALENCASTRO, 1999, p. 120). Entre seus comentadores, Raymundo Faoro (1997) chamou a atenção para a "história visceralmente artística" narrada por Nabuco, "história criadora, encharcada de arte e banhada de nostalgia”, que não deixava de ser pautada pela interpretação dos fatos e a pesquisa escrupulosa das fontes disponíveis. Outras leituras mais recentes, como a de Luís Felipe de Alencastro, destacam na obra o "variado e copioso acervo documental" mobilizado pelo escritor-político abolicionista para traçar, mais do que a história de uma vida, a análise da sociedade e do cenário político do Segundo Reinado (ALENCASTRO, 1999, p. 119). A despeito do vínculo estreito entre os textos de Joaquim Nabuco e a política de seu tempo, no conjunto de seus escritos, que nunca deixou de ser reconhecido pelo próprio autor ou por seus contemporâneos, $U m$ Estadista do Império permanece sendo considerado como o seu mais importante trabalho historiográfico (MARSON, 2008, p. 277). 
A menção à obra, que se tornou referência da literatura política brasileira, justifica-se como mote inicial das reflexões que apresento a seguir por condensar indicações valiosas acerca das relações entre escrita biográfica, história e historiografia e, em especial, dos contatos profícuos entre os dois gêneros no Brasil do século XIX.

\section{A aposta biográfica}

No momento em que Nabuco lançou-se ao projeto de escrita da biografia de seu pai, o gênero já ocupava um lugar tangivelmente demarcado no âmbito da instituição para a qual convergiu parte significativa da produção letrada brasileira no Oitocentos. No material estampado nas páginas da revista do Instituto Histórico e Geográfico Brasileiro (IHGB) e, sobretudo, na seção dedicada às vidas de brasileiros ilustres, desde a sua criação, em 1839, até o final do século XIX, a escrita de biografias pode ser compreendida não somente como rito e estratégia de fixação da memória, mas como um problema historiográfico. Isso porque a aposta biográfica dos sócios do IHGB, mesmo justificada pela vocação moralizante dessa modalidade de escrita, permaneceu submetida a uma ambição de verdade análoga à da historiografia (OLIVEIRA, 2011).

Nesse contexto, dois aspectos imbricados estiveram na base da escrita de textos biográficos publicados no periódico da agremiação. O primeiro deles, de caráter explicitamente político, refletia expectativas e impasses no trabalho de conciliação simbólica dos elementos díspares da formação social e histórica do Brasil, sob a égide do regime monárquico (ENDERS, 2004). A par disso, é possível compreender os usos da biografia como parte da construção de uma retórica da nacionalidade, ou seja, como um conjunto de estratégias discursivas utilizadas com vistas a persuadir os brasileiros de que, a despeito da natureza heterogênea e compósita de sua formação social, partilhavam de um mesmo passado, e, por consequência, de uma mesma origem e de uma mesma identidade (CEZAR, 2011, p. 48).

Indissociável do primeiro, o outro aspecto da atividade biográfica no período remete às suas implicações epistemológicas, na 
medida em que a prática do gênero acompanhou o processo de institucionalização da pesquisa e da escrita da história (CEZAR, 2003). Deste modo, o projeto de elaboração do panteon de brasileiros ilustres, com sua forte ênfase no culto dos homens exemplares, justificado pelos argumentos da fórmula antiga historia magistra vitae, não esteve em descompasso com a modernização da historiografia, mas sim, em muitos casos, compartilhou com esta as exigências da comprovação documental (OLIVEIRA, 2011, p. 77-99). ${ }^{2}$ É pertinente destacar essa particularidade do caso brasileiro, pois a importância atribuída à biografia como gênero nobre de escrita da história não foi sustentada com convicção similar em outros contextos letrados (DOSSE, 2009, p. 170-173). ${ }^{3}$

A noção-chave implícita na formação do panteon brasileiro é a do grande homem das Luzes, louvado por personificar a excelência do homem comum, letrado, benfeitor da humanidade e, sobretudo, dotado de virtudes exemplares como servidor do Estado (BONNET, 1998, p. 29, tradução nossa). A publicação regular e em série de biografias sugere, portanto, que os personagens biografados encarnavam valores coletivos celebrados pela sociedade política do Segundo Reinado. A própria noção iluminista de "grande homem", subjacente aos critérios de eleição dos indivíduos biografados no contexto oitocentista, pode ser compreendida a partir de um regime de historicidade fundado na contiguidade entre passado, presente e futuro, remetendo à ideia de perfectibilidade do gênero humano. Nas palavras de François Hartog, a figura do grande homem, em contraponto ao modelo do herói épico plutarquiano, assinalaria "[...] um momento de aceleração do tempo, cujas marcas estão dentro de sua própria vida e nele próprio” (HARTOG, 2001, p. 30, tradução nossa). ${ }^{4}$

Assim, uma referência central para as obras biográficas no século XIX são as reflexões filosóficas do francês Victor Cousin. Correntemente citado pelos sócios do IHGB, Cousin dedicara, em seu Cours de l'histoire de la philosophie (Paris, 1828), uma das lições ao tema dos "grandes homens", definindo-os como indivíduos eminentes capazes de "encarnar" os povos e as coletividades (GÉRARD, 1998, p. 37-38). ${ }^{5}$ Desse modo, o "espírito geral de um povo" manifestar-se-ia nos indivíduos notáveis: "[...] abre os livros 
de história e não verás senão nomes próprios; os historiadores têm fortes razões de se ocupar dos grandes homens, é necessário que eles se ocupem desses personagens pelo que, de fato, são: não os 'senhores', mas os representantes daqueles que não aparecem na história” (COUSIN, 1841, p. 299-300).

As reflexões de Cousin estão fortemente impregnadas pela ideia de "grande indivíduo histórico universal", ancorada na filosofia da história de Hegel. Para o filósofo alemão, os grandes indivíduos históricos seriam "instrumentos de um fim mais alto e vasto, do qual nada sabem - que realizam inconscientemente”. As individualidades histórico-mundiais deveriam, portanto, ser reconhecidas como heroínas, dotadas da "visão do que era necessário e do que era oportuno" em sua época, "[...] as suas ações, as suas palavras, são os melhores desse momento" (HEGEL, 2008, p. 32-33).

No Oitocentos, embora uma história universal se impusesse como corolário das ambições da disciplina quanto à apreensão dos fenômenos históricos em sua totalidade, o conceito de nação se constituirá como o horizonte instransponível sob o qual se ordenará simbolicamente o passado, o presente e o futuro (HARTOG, 2000, tradução nossa). Aos historiógrafos caberia, enfim, a tarefa de conciliar o novo interesse pela marcha das forças coletivas no tempo e a identificação dos seus protagonistas; pois, na medida em que esboçavam essas narrativas, assumiam o papel de grandes árbitros, estabelecendo a correlação entre as ações individuais e a genealogia da nação (FABRE, 1998, p. 272). À ideia de nação vigente no contexto oitocentista, articular-se-ia uma noção específica de temporalidade como uma qualidade de desenvolvimento geral, intrínseca e imanente à realidade. Sob essa perspectiva, “[...] não haveria história fora da nação ou de certo grupo humano da qual essa história emanaria, tampouco nenhum acontecimento histórico seria possível independentemente de algo que aconteça” (PALTI, 2002, p. 44-45, tradução nossa).

Acompanhando, portanto, o advento das filosofias da história, os dilemas envolvidos na modernização da historiografia ao longo do Oitocentos e nas décadas iniciais do século XX, introduziram algumas indagações importantes: em que medida aqueles que se propunham a escrever vidas poderiam ignorar a marcha das forças 
coletivas no tempo, ou, até mesmo, deixar de considerar que as ações de seus biografados inscreviam-se em uma instância mais vasta e ampliada do que o estrito lapso temporal de uma existência singular? Até que ponto foi possível sustentar a convicção, justificativa da aposta biográfica dos letrados oitocentistas, de que as vidas exemplares dos indivíduos ilustres permitiam um acesso privilegiado à história de épocas passadas? E, em decorrência disso, como pensar os indivíduos enquanto portadores da mudança no curso dos acontecimentos? Como articular individualidade, ação histórica e exemplaridade no texto biográfico?

\section{Modulações do biográfico}

Tal como foi praticada ao longo do século XIX no Brasil, é possível identificar duas modulações significativas na escrita biográfica, que, mesmo não estando separadas por uma linha demarcatória rígida, apontam para algumas nuances nos usos do biográfico e suas intersecções com o gênero histórico.

A primeira delas encontra-se explicitamente delineada no projeto de constituição de um espaço específico destinado à publicação de biografias na revista do IHGB. Idealizado por Januário da Cunha Barbosa como um trabalho sistemático de memória e uma estratégia eficaz no combate ao esquecimento, a proposta se materializou nas inúmeras narrativas das vidas de brasileiros ilustres, cujo objetivo comum era registrar e evidenciar para a posteridade as suas virtudes morais e suas ações exemplares como servidores do Estado nacional. Nesse momento, a mobilização do preceito antigo historia magistra vitae como argumento-chave do projeto historiográfico do IHGB tornava desnecessária qualquer tipo de partilha ou distinção pontual entre os gêneros: as vidas de indivíduos notáveis do passado mereciam ser narradas para permanecer a salvo do esquecimento produzido pelo tempo e para guiar, com seus ensinamentos morais, as ações no presente, assim como um livro de história (BARBOSA, 1839).

Com essa proposta, a escrita biográfica orienta-se por um sentido encomiástico e memorialístico explícito, adquirindo a 
dimensão de uma tarefa monumental e coletiva, o que está implícito tanto na disposição em série das vidas dos grandes homens do passado nacional quanto na mobilização variada de autores para a sua composição. Assim, ao longo do Oitocentos, um panteon de brasileiros ilustres se constituiu de modo regular e cumulativo, não obstante a ausência de qualquer reflexão prévia acerca dos critérios de eleição das celebridades, afora a evocação explícita da tópica das "letras, armas e virtudes" no título da seção nas páginas da revista do IHGB, com textos assinados por Januário da Cunha Barbosa, Francisco Adolfo de Varnhagen, Joaquim Caetano Fernandes Pinheiro, Joaquim Norberto de Sousa Silva, entre outros. Um olhar panorâmico sobre essa galeria de retratos de personagens célebres remete à questão: para citar apenas alguns desses biografados, o que haveria em comum entre os poetas José Basílio da Gama, Gregório de Matos, Cláudio Manoel da Costa, os padres Antônio Pereira de Souza Caldas, José Maurício Nunes Garcia, Frei Leandro do Sacramento e os militares Salvador Correa de Sá Benevides, Martim Afonso de Souza, André Vidal de Negreiros? Como apreender ou vislumbrar os ensinamentos morais e o valor exemplar dessas vidas?

Se considerarmos a forma breve dessas notícias biográficas em seu conjunto, é possível perceber que a exemplaridade se apresenta ao leitor pelo efeito de recursos narrativos capazes de demonstrar a unidade de uma vida, cujo propósito é desvelado contínua e linearmente no relato dos episódios sucessivos da existência em ordem cronológica, do nascimento até a morte (HAMPTON, 1990, p. 23-24). Assim, sob a chave de uma retórica da nacionalidade, as biografias dos brasileiros ilustres se fundavam na correlação entre as suas trajetórias singulares e o tempo histórico da nação, mediante o elogio das suas virtudes morais como modelo para o presente e a fixação da memória das suas ações exemplares para a posteridade.

É desse modo que alguns membros da família de Francisco de Lemos de Faria Pereira Coutinho, nascido no Brasil e nomeado reitor da Universidade de Coimbra em 1770, despontam como representantes dessa exemplaridade que, segundo a prescrição de Januário Cunha Barbosa, deveria justificar a escrita de notícias biográficas dos brasileiros distintos. Em texto assinado por ele próprio, 
a tópica da virtuosidade nas letras e nas armas, que se estampa no título da seção de biografias da revista da agremiação, é usada para definir a trajetória de vida do seu biografado, Clemente Pereira de Azeredo Coutinho, irmão de Francisco de Lemos, e governador da capitania do Maranhão:

Familias ha em que o empenho de adquirir honra e gloria no serviço da patria constitue uma herança, que vai passando de paes a filhos. [...] De quatro irmãos que eram, descendentes de um honrado Brasileiro, que entre seus avós contava muitos illustres servidores do Estado, foi Pereira de Azeredo o que desviando-se da carreira commumente seguida n'esses tempos dos mancebos illustres, procurou a gloria das armas apoiada na gloria das lettras. (BARBOSA, 1842, p. 88).

Por sua vez, na biografia dedicada a Frei Francisco de Monte Alverne, Domingos Gonçalves de Magalhães se apoia na convivência próxima que tivera com o biografado não apenas como condição privilegiada para lhe prestar um "tributo de saudade", mas sobretudo para afirmar a autoridade do discurso biográfico em louvor das qualidades exemplares do pregador imperial:

[...] em vida lhe dediquei cânticos de amizade e de admiração, não comprados por favores; nada tinha esse frade que dar; de nada precisava do mundo, além d'essa amizade pura, mantida pelas ideas; e jamais dei louvores a quem por virtudes os não merecesse. (MAGALHÃES, 1882, p. 393) A vida de frei Francisco de Monte-Alverne, que se estendeu a 74 annos, foi a de um religioso literato e exemplar, que nunca se envolveu nas questões politicas, que agitarão os homens de seu tempo; não por indiferença, mas por dignidade do habito, que sempre respeitou. Sua arena era o púlpito e a cadeira. "Sou frade (dizia ele muitas vezes) e frade morrerei”. E esse frade é uma das glorias do Brazil! (Ibid., p. 404). 
A exemplaridade das vidas dos indivíduos ilustres do panteon nacional não se torna evidente, portanto, sem certa presunção antecipada de um ajuizamento moral das suas ações. E, nesse trabalho, biógrafos e historiadores, ambos movidos pelo imperativo de combater o esquecimento e a ação corrosiva do tempo, dado que cumprem o encargo de guardiões da memória, não deixam de eleger e fixar a grandiosidade de certas trajetórias individuais precisamente por seu serviço a res publica, como exemplos edificantes a serem compartilhados socialmente. ${ }^{6}$

Os usos da biografia, enquanto parte constituinte do projeto historiográfico do IHGB, não podem ser explicados unicamente como expressão do gosto literário dos sócios fundadores, na medida em que a profusão do corpus biográfico se renovou nas gerações subsequentes. Fora do espaço da revista do Instituto, outras publicações inspiradas no gênero "vidas ilustres", além de se mostrarem igualmente afinadas à modalidade biográfica encomiástica e moralizante, revelavam também pretensões e alcances ampliados. ${ }^{7}$ É o caso do Plutarco Brazileiro (1847), de João Manoel Pereira da Silva, em que é possível perceber uma sutil, mas não menos significativa, modulação do biográfico. Apresentada como "a historia do Brazil em algumas épochas", a opção de Pereira da Silva pelo gênero biográfico se justificava, em suas palavras, pois "[...] narrando a historia dos homens illustres do seu paiz conjunctamente com a dos grandes successos, que tiveram logar durante suas vidas, mais agradava a seus leitores" (SILVA, 1847, p. vii-viii). As pretensões historiográficas do projeto se tornaram mais explícitas na segunda versão da obra, ampliada e rebatizada com o título Os varões illustres, durante os tempos coloniaes. Posta em epígrafe à nova edição, uma frase de Victor Cousin reforça a utilidade e a eficácia magisterial da biografia, em termos semelhantes aos que Pereira da Silva já havia apresentado na primeira versão: nas vidas dos personagens destacados no "teatro do mundo", estava a parte mais agradável e instrutiva da história. ${ }^{8}$

Assim como o autor do Plutarco Brazileiro, Manuel Araújo Porto Alegre concebia a narrativa das vidas dos homens notáveis como via de acesso privilegiado ao tempo histórico em que eles viveram: 
Conhecida a biographia de todos os homens salientes de uma épocha, seja qual for a sua acção civilisadora, está conhecida a historia d'aquelles tempos; porque nos seus actos, nas suas idéas, nos seus resultados, está o movimento geral, as peripécias do drama animado da sociedade, onde cada um d'estes indivíduos foi actor e compositor. (PORTO ALEGRE, 1856, p. 353)

É impossível não associar a frase à ideia de Thomas Carlyle de que "[...] a vida social é resultado de todas as vidas individuais que compõem a sociedade", ou, ainda, de que "[...] a história é a essência de inúmeras biografias” (CARLYLE, 1852, p. 255, tradução nossa). ${ }^{9}$ Cabe salientar que não se identificam menções diretas ao escritor escocês nos textos impressos no periódico do Instituto, o que não impediu que a escrita de biografias seguisse justificada por muitos dos sócios com base em concepções análogas, permanecendo exaltada como fonte de exemplos das mais altas virtudes morais e patrióticas.

Afora a sua eficácia como instrumento de pedagogia cívica e moral, as vidas e feitos dos grandes personagens revelavam o "movimento geral" da história. Não era diferente da concepção formulada pelo primeiro secretário do IHGB, cônego Joaquim Fernandes Pinheiro, em 1864: “[...] nomes há que symbolisam uma época, um povo, uma civilisação; poderosas individualidades, que, atrahindo a si todas as attenções, concentram em sua pessoa as idéas e os feitos de milhares de homens: Carlos Magno é a Idade Média, Napoleão I a Revolução Franceza” (REVISTA DO IHGB, 1864, p. 394).

Idêntico argumento estava presente no parecer que julgara a Noticia acerca da vida e obras de João Francisco Lisboa, de Antônio Henriques Leal, como "[...] uma biographia com todas as dimensões de historia política e litteraria” (REVISTA DO IHGB, 1866, p. 408). Nesse caso, o grande mérito do autor estava precisamente em ultrapassar as tarefas de "simples biógrapho" para se alçar à condição de historiador eloquente, devido à forma como conectava a vida do biografado ao quadro político do seu tempo. 
A circumstancia de ser João Francisco Lisboa chefe de um partido e redigir uma folha em sentido liberal, serviu de elo de cadêa a seu habilíssimo biographo para reproduzir em quadro fiel e resumido a historia política de então. Um escriptor menos amestrado ter-se-ia limitado a narrar a parte activa que o redactor da Chronica tomou na reprovação do assassinato e accusação do assassino, sem descever o estado do paiz n'aquella épocha, e daria a seu quadro um interesse puramente individual, ao passo que o Sr. Dr. Leal soube pela ligação sobredita dar ao seu um interesse todo collectivo, sem todavia deixar de pôr em relevo o grandioso vulto que pinta. (REVISTA DO IHGB, 1866, p. 411-412).

Nas citações destacadas anteriormente, vislumbra-se uma segunda modulação do biográfico que, se não extrapola de todo o escopo memorialístico e encomiástico daquela primeira, apresenta ambições explícitas de fornecer, nas histórias de vidas ilustres, chaves possíveis de acesso à apreensão e representação dos quadros gerais do passado. Em relação àquela de sentido marcadamente moralizante, esta forma de conceber a biografia está fundada menos na elaboração de retratos singulares de virtudes e de exemplos morais do que no reconhecimento do valor heurístico das vidas dos grandes homens na apreensão da história, pensada no singular coletivo. Com isso, não suponho que entre a biografia moral e a de modulação de amplitude historiográfica exista um salto "evolutivo", capaz de configurar uma hierarquia ou algo similar à substituição de um princípio de justificação - nesse caso, o antigo topos da historia magistra vitae, crucial para circunscrever a função pedagógica da primeira - por uma concepção que se esvaziaria de qualquer pretensão magisterial, alinhando-se, por conseguinte, a um conjunto de noções que, grosso modo, identificam-se como "modernas".

Para reforçar o argumento, vale destacar que a configuração do campo semântico da noção de biografia, usual a partir de meados do século XVIII, fez-se mediante a oposição entre um sentido próprio (o bios dos gregos ou relato de uma vida) e um sentido metonímico (denotando os acontecimentos de uma vida), o que remete à dualidade de significado similar a do conceito moderno 
de história como narração e conjunto de fatos que se produzem no tempo (MADELÉNAT, 1984, p. 11-20). ${ }^{10}$ Tal duplicidade de sentido se torna relevante, porquanto uma vida não adquire sua verdadeira e definitiva "realidade" senão por sua configuração através de uma unidade narrativa. Enfim, para ambas - história e biografia - uma só palavra passaria a designar, ao mesmo tempo, a operação e o artefato textual que dela resulta.

Se a biografia, sob todas as suas formas, permaneceu disponível como recurso eficaz na elaboração da experiência do tempo e no combate ao esquecimento, talvez isso se explique pelo fato de que o gênero compartilhou, sob muitos aspectos, o dilema epistemológico que perpassou a operação historiográfica na modernidade, com sua pretensão de controlar os riscos de parcialidade e de ajuizamento moral, implicados na representação do passado (REVEL, 2010). Por conta das condições favoráveis a essa aproximação, muitos letrados brasileiros oitocentistas não dispensaram a prática concomitante da biografia e da escrita histórica, tendo por horizonte a tessitura dos elos possíveis entre o presente, o passado e o futuro. Portanto, a despeito das novas exigências disciplinares, nem a história nem a biografia precisariam renunciar terminantemente à antiga função magisterial em nome dos modernos axiomas de cientificidade. E, de modo específico, a composição dos panteões biográficos no Oitocentos pode ser compreendida como manifestação tangível e efetiva não apenas da permanência, mas das mobilizações renovadas do topos da historia magistra vitae no contexto de elaboração das historiografias nacionais. ${ }^{11}$

Contudo, a despeito dos contatos tão próximos e profícuos entre ambas, a paulatina conquista da autonomia disciplinar da história não teria contribuído para relegar a biografia a um papel coadjuvante, pelo caráter particular e singular intransponível do seu objeto, mesmo frente às ambições totalizantes da escrita da história? Como alvo fácil de suspeitas e interdições, não seria justamente o biográfico denunciado como um dos "ídolos da tribo dos historiadores" (SIMIAND, 2003, p. 109-116), a ser sacrificado no altar, o que elevaria o estatuto da história de gênero literário à disciplina científica? 


\section{Das vidas exemplares aos usos heurísticos da biografia}

No Brasil do Oitocentos, em especial em suas décadas finais, se não é possível identificar um "eclipse" da biografia, nos termos de François Dosse, existem indícios de que a defesa do estatuto historiográfico de sua escrita não se sustentava tão consensualmente. Sabemos que, entre os autores das biografias incluídas na galeria de ilustres do IHGB, figuraram nomes como os do cônego Fernandes Pinheiro, Joaquim Norberto e muitos outros envolvidos com o projeto mais amplo de escrita da história nacional. Poucos desses letrados, no entanto, foram tão bem sucedidos na instrumentalização da pesquisa e da escrita biográficas a favor do conhecimento histórico quanto o Visconde de Porto Seguro. Exemplo paradigmático da mobilização de episódios eminentemente biográficos na operação historiográfica, Evandro Santos identificou há pouco tempo as inúmeras digressões dedicadas a personagens históricos e, em especial, aos protagonistas heroicos da guerra holandesa, como recurso heurístico fundamental na densa trama narrativa da História Geral do Brasil, de Varnhagen (SANTOS, 2012, p. 88-105).

Capistrano de Abreu não figura entre os letrados que se consagraram à escrita de biografias como aqueles já citados, o que não significa que tenha ignorado os recursos da pesquisa biográfica. Ainda é preciso mapear melhor, em sua vasta correspondência ativa, as referências ao assunto. $\mathrm{O}$ que pretendo destacar aqui são dois momentos distintos do contato entre Capistrano e o tema da biografia. Nos ensaios e artigos que publicou em periódicos da Corte nesse período, destaca-se uma resenha, escrita em 1877, com o sugestivo título de Biografia, na qual Capistrano desfere o seu arsenal crítico contra a História da Fundação do Império Brasileiro, de João Manuel Pereira da Silva (ABREU, 1976). A princípio, o título poderia ser explicado pelo nome do autor da obra resenhada estar associado ao projeto biográfico denominado $O$ Plutarco Brazileiro, já mencionado, que dividira opiniões dentro do IHGB. Mas, a despeito desse detalhe, por que Capistrano optaria por nomear de "biografia" o comentário endereçado a uma obra que se propunha traçar, em três copiosos volumes, uma história do Império? Ao longo do artigo, não existem remissões, tampouco há 
outras referências diretas que justifiquem explicitamente o uso da expressão. Portanto, a palavra "biografia" condensaria a objeção central dirigida ao conselheiro? Na visão de Capistrano, Pereira da Silva apresentava "[...] um livro pesado, cheio de páginas sem graça e inçado de erros históricos", e o seu maior equívoco consistia “[...] em supor que se escreve história com a mesma facilidade com que se improvisa um romance" (ABREU, 1976, p. 38). Não obstante o esforço ambicioso da empreitada e a aplicação laboriosa de seu autor, a obra não possuía valor historiográfico.

Dar notícias de batalhas, fazer desfilar diante dos olhos do leitor os nomes de coronéis e majores, pintar o entusiasmo que se apoderou deste ou daquele grupo a ver D. Fuão ou D. Sicrano, será tudo quanto se quiser, menos escrever história. A história quando é escrita com precipitação, onde o autor, poeta ou romancista, dá largas à sua imaginação, deixa de ser história, é romance, é poema, deleita, agrada, distrai, mas não instrui, e não adianta idéia alguma, e livros que não adiantam idéias, de pouca utilidade são. Ou história verdadeira ou romance, tem-se a escolher [...]. (ABREU, 1976, p. 39).

Para Capistrano, não havia dúvida: Pereira da Silva não lograra produzir uma obra histórica, nem sequer algo próximo a um romance histórico. Portanto, pela impossibilidade da plena aprovação da sua História da Fundação do Império Brasileiro, talvez se justificasse a escolha da legenda pejorativa de "biografia". Ainda na resenha, além do título capcioso, o aspecto mais relevante da crítica está precisamente na dupla exclusão com que Capistrano sustenta a sua concepção de uma "história verdadeira" que não se confunde com a narrativa de acontecimentos particulares ("notícias de batalhas"; "nomes de coronéis e majores") e não se faz pelo uso da imaginação, própria à escrita do romance e do poema (OLIVEIRA, 2013, p. 35-36).

Mas, afora a sua usual mobilização do argumento crítico dirigido às obras dos historiadores, "inexatos e descuidados com as fontes”, como não reconhecer a fragilidade das fronteiras entre narrativas verdadeiras e imaginadas, na medida em que a operação 
da escrita - histórica ou biográfica - implica que o historiador e o biógrafo ocupem o lugar e o ponto de vista de um narrador? $\mathrm{Na}$ condição de "gênero impuro", que não se define por meio de uma partilha similar com a ficção, os usos da biografia com pretensões historiográficas não potencializariam o problema, tornando ainda mais evidentes os paradoxos implicados na representação do passado?

\section{Considerações finais}

O ensaio O Duque de Caxias é um dos raros trabalhos biográficos de Capistrano de Abreu e a partir dele podem ser apresentadas algumas considerações finais. A publicação do texto, na Gazeta de Notícias, em agosto de 1903, coincidiu com o centenário de nascimento do personagem cujo nome se estampa no título, um dos mais emblemáticos da história da formação do Estado imperial. Comparado à disposição factual e cronológica das narrativas do gênero, o texto apresenta o estilo despojado e direto que se tornou um dos traços distintivos do autor dos Capítulos da História Colonial, marcado pela prosa enxuta, quase telegráfica, na qual se combinam concisão, eloquência e, por vezes, singeleza.

Foi um decennio favorável o de 50 . O imperador contava com vinte e cinco annos e a nação sentia-se igualmente moça. Terminara o período revolucionário, guerras estrangeiras felizes varreram a atmosfera, a extincção do trafico tolhia novos insultos da soberania nacional, encurtava a distancia do velho mundo com a navegação a vapor do Atlantico. Mauá canalizava milhões esterlinos, silvavam as primeiras locomotivas; as letras rasgavam os clássicos andrajos coloniaes; falava-se em opera nacional, em theatro nacional [...]; afinal delia-se a macula original da nossa gente, a "apagada e vil tristeza”, de que já se queixava o épico lusitano [...] (ABREU, 1932, p. 32-33).

A passagem descreve o momento de ápice da carreira política e militar de Luiz Alves de Lima, após as sucessivas campanhas 
vitoriosas na pacificação do Rio Grande do Sul e na Guerra do Paraguai. A breve biografia de Caxias sintetiza e se confunde com o momento histórico de afirmação e plenitude do projeto político do Estado imperial. Embora não seja possível identificar uma explícita adesão ao gênero no conjunto da obra de Capistrano, trata-se, sem dúvida, de um texto biográfico com amplitude e alcance historiográficos. Entre a escrita de uma vida e a narração da história, caberia ao leitor vislumbrar, enfim, a "vista lateral de uma época", da qual falara Nabuco no prefácio da biografia de seu pai.

No Brasil imperial, as relações entre biografia e história não se estabeleceram por uma única via, mas foram marcadas por modulações, tanto na amplitude quanto no alcance dessas aproximações, sempre submetidas às demandas gerais de configuração da experiência do tempo. Como ficou demonstrado na postura de historiadores das décadas finais do Oitocentos, se o biográfico não foi o gênero que conquistou uma adesão plena, também não chegou a ser objeto de uma recusa radical, na medida em que, mobilizado por seu valor heurístico, mostrou-se eficaz em evidenciar as intersecções entre as existências singulares dos indivíduos notáveis e a marcha geral e inexorável da história.

\section{BIOGRAPHY AND HISTORIA MAGISTRA VITAE: ON THE EXEMPLARITY OF ILLUSTRIOUS LIVES IN NINETEENTH-CENTURY BRAZIL}

Abstract: The article discusses the relationship between biographical writing and historiography, analyzing the notion of exemplarity underlying narrative of the lives of illustrious Brazilians, published in the Instituto Histórico e Geográfico Brasileiro journal, in nineteenth-century. In the literate context of imperial Brazil, it is possible to identify two significant modulations in the forms of biography, the first driven by a moralizing, laudatory and memorialistic sense and the second driven by ambition to provide heuristics access keys to the apprehension and representation frameworks of the past. The central argument is that in imperial Brazil, the contacts between biography and history were not established by a single route, but were marked by such modulations and subject to the general demands of the experience of time configurations.

Keywords: Biography. Historia Magistra Vitae. Historiography. 


\section{Notas}

${ }^{1}$ Nas citações dos textos editados no século XIX, será mantida a grafia e a pontuação originais.

${ }^{2}$ Para uma análise da teoria exemplar da história, desde os filósofos estóicos romanos, e a justificação dos usos dos exempla entre os historiadores antigos, ver NADEL, 1965. Nos estudos de Reinhart Koselleck sobre o advento do conceito moderno de história, a fórmula retórica da historia magistra vitae, que orientou as formas de se conceber a historiografia, adquire sentido por se associar a um tipo específico de concepção do tempo e a "um espaço de experiência contínuo" entre passado, presente e futuro (KOSELLECK, 2006, p. 42).

${ }^{3}$ Sobre a biografia no contexto lusitano do século XIX, especialmente em Oliveira Martins, ver CATROGA, 2004.

${ }^{4}$ Acerca da noção de regime de historicidade, cf. HARTOG, 2013.

${ }^{5}$ Ao identificar a formação da elite política do Brasil imperial, José Murilo de Carvalho refere-se a Cousin como autor que talvez tenha sido a maior influência intelectual sobre os letrados brasileiros até 1870. Cf. CARVALHO, 1981, p. 70.

${ }^{6}$ Nessa direção, Márcia de Almeida Gonçalves, em seu estudo sobre o contexto romântico brasileiro, argumenta que, nos trabalhos de memória, de construção autobiográfica de si e de escrita das histórias de vida, as narrativas das trajetórias individuais adquiriam o seu sentido a partir da experiência coletiva de edificação da própria história nacional, confundindo-se com ela, em uma espécie de jogo metonímico entre a parte e o todo, entre indivíduo e nação. A autora faz menção à diversidade de usos, formas e funções da escrita biográfica nesse período, sem adentrar, contudo, em uma análise mais pontual desses textos. Cf. GONÇALVES, 2009.

${ }^{7}$ Entre essas publicações, cito as mais importantes: a Galeria dos brasileiros ilustres (os contemporâneos) (1861), de Sébastien Auguste Sisson; Brasileiras célebres (1862), Norberto de Sousa; Dicionário biographico de brasileiros célebres (1871), da Editora Laemmert; Ano biographico brazileiro (1876), de Joaquim Manuel de Macedo; O Pantheon Fluminense: Esboços biographicos (1880), de Prezalindo Lery Santos; e, por fim, Dicionário Bibliográfico Brasileiro, de Augusto Victorino Alves Sacramento Blake, publicado entre 1883 e 1902. Para uma análise desses catálogos biográficos, cf. ENDERS, 2004, p. 183-245.

8 "L'histoire n'a point de partie plus agréable et plus instructive que la vie particulière des grands et vertueux personnages qui on fait figure distinguèe sur le théatre du monde". (COUSIN apud SILVA, 1868).

Anos 90, Porto Alegre, v. 22, n. 42, p. 273-294, dez. 2015 
9 Para uma análise dos argumentos de Carlyle sobre a história, ver LORIGA, 2008 e 2011, p.53-80.

${ }^{10}$ Emprestadas do grego tardio, "biografia" e "biógrafo" são registradas pelos dicionários de língua inglesa e francesa no decorrer do século XVIII. Seus derivados, mais raros, formam-se no século XIX. Nascida no auge de um período de laicização acelerada, a palavra biografia ("tipo de história que tem por objeto a vida de uma só pessoa”, segundo Littré) parece denotar uma obra com rigor "científico", em oposição implícita às formas antigas (panegírico, elogio, oração fúnebre) de eloquência sacra ou oficial (MADELÉNAT, 1984, p. 14).

${ }^{11}$ Uma discussão oportuna do argumento acerca da dissolução ou permanência dos usos da fórmula da "história mestra da vida", experiência moderna do tempo e historiografia brasileira do século XIX, encontra-se em ARAÚJO, 2011, p. 131-147.

\section{Referências}

ABREU, João Capistrano de. Biografia. In: Ensaios e Estudos. 4. série. Rio de Janeiro: Civilização Brasileira, 1976. p. 37-41.

. O Duque de Caxias. In: Ensaios e Estudos. 2. série. Rio de Janeiro: Sociedade Capistrano de Abreu; Livraria Briguiet, 1932. p. 9-35.

ALENCASTRO, Luiz Felipe de. Joaquim Nabuco: um estadista do Império. In: MOTA, Lourenço Dantas (Org.). Introdução ao Brasil: um banquete no trópico. 2. ed. São Paulo: Editora Senac, 1999.

ARAÚJO, Valdei Lopes de. Sobre a permanência da expressão historia magistra vitae no século XIX brasileiro. In: NICOLAZZI, Fernando; MOLLO, Helena Miranda; ARAÚJO, Valdei Lopes de (Org.). Aprender com a história? O passado e o futuro de uma questão. Rio de Janeiro: Editora FGV, 2011. p. 131-147. BARBOSA, Januário da Cunha. Discurso. Revista do IHGB, Rio de Janeiro, 3. ed., tomo 1, n. 1, p. 9-17, 1839.

. Biographia: Clemente Pereira de Azeredo Coutinho e Melo. Revista do $I H G B$, Rio de Janeiro, tomo IV, n. 13, p. 88-91, 1842.

BONNET, Jean-Claude. Naissance du Panthéon: Essai sur le culte des grands hommes. Paris: Fayard, 1998. 
CARLYLE, Thomas. On history. In: . Critical and miscellaneous essays. Philadelphia: Hart, Carey \& Hart, 1852, vol. 5, p. 219-223.

CARVALHO, José Murilo de. A construção da ordem. Brasília: Editora UnB, 1981. CATROGA, Fernando. O magistério da história e exemplaridade do "grande homem”: a biografia em Oliveira Martins. In: PÉRES JIMÉNEZ, Aurélio; FERREIRA, José Ribeiro; FIALHO, Maria do Céu (Coord.). O retrato literário e a biografia como estratégia de teorização política. Coimbra: Imprensa da Universidade de Coimbra; Universidade de Málaga, 2004. p. 243-288.

CEZAR, Temístocles. Livros de Plutarco: biografia e escrita da história no Brasil do século XIX. Métis: história \& cultura, Caxias do Sul, v. 2, n. 3, p. 73-94, jan./jun. 2003.

. L'écriture de l'histoire au Brésil au XIXe siècle: essai sur 1 utilisation des modèles anciens et modernes de l'historiographie. Historiografías, revista de historia y teoría, Zaragoza, v. 2, p. 45-65, jul./dez. 2011.

COUSIN, Victor. Cours de l'histoire de la philosophie: Introduction a l'histoire de la philosophie. Paris: Didier, 1841.

DOSSE, François. O desafio biográfico: escrever uma vida. São Paulo: EDUSP, 2009.

ENDERS, Armelle. Les visages de la Nation: Histoire, héros nationaux et imaginaire politique au Brésil (1822-1922). 2004. Tese de doutorado-Université Paris 1 - Panthéon-Sorbonne, Paris.

FABRE, Daniel. L’atelier des héros. In: CENTILIVRES, Pierre; FABRE, Daniel; ZONABEND, Françoise (Dir.). La fabrique des héros. Paris: Éditions de la Mason des sciences de l'homme, 1998. p. 233-318.

FAORO, Raymundo. História e arte. In: NABUCO, Joaquim. Um estadista do Império. 5. ed. v. 1. Rio de Janeiro: Topbooks, 1997. p. 21-30.

GÉRARD, Alice. Le grand homme et la conception de l'histoire au XIXe siècle. Romantisme, Lyon, v. 28, n. 100, p. 31-48, 1998.

GONÇALVES, Márcia de Almeida. Histórias de gênios e heróis: indivíduo e nação no Romantismo brasileiro. In: GRINBERG, Keila; SALLES, Ricardo (Org.) O Brasil imperial. v. 2: 1831-1870. Rio de Janeiro: Civilização Brasileira, 2009. p. 425-465.

HAMPTON, Timothy. Writing from history: the rhetoric of exemplarity in Renaissance literature. New York: Cornell University, 1990. 
HARTOG, François. La France, l'objet historique. Le Monde des Débats, Paris, n. 19 , nov. 2000.

. Plutarque entre les Anciens et les Modernes. In: PLUTARQUE. Vies parallèles. Paris: Gallimard, 2001.

. Regimes de historicidade: presentismo e experiências do tempo. Belo Horizonte: Autêntica, 2013.

HEGEL. História filosófica. In: GARDNER, Patrick. Teorias da História. 4. ed. Lisboa: Fundação Calouste Gulbenkian, 1995. p. 73-88.

KOSELLECK, Reinhart. Futuro Passado: contribuição à semântica dos tempos históricos. Rio de Janeiro: Contraponto; Editora PUC-Rio, 2006.

LORIGA, Sabina. A biografia como problema. In: REVEL Jacques. Jogos de escalas: a experiência da microanálise. Rio de Janeiro: Editora Fundação Getúlio Vargas, 1998.

. O pequeno x: da biografia à história. Belo Horizonte: Editora Autêntica, 2011.

MADELÉNAT, Daniel. La Biographie. Paris: PUF, 1984.

MAGALHÃES, Domingos José Gonçalves de. Biografia do padre-mestre Frei Francisco de Monte Alverne [1859]. Revista do IHGB, Rio de Janeiro, tomo LIV, p. 391-404, 1882.

MARSON, Izabel Andrade. Política, história e método em Joaquim Nabuco: tessituras da revolução e da escravidão. Uberlândia: EDUFU, 2008.

NABUCO, Joaquim. Um estadista do Império: Nabuco de Araújo: sua vida, suas opiniões, sua época. Tomo 1. Rio de Janeiro: H. Garnier, 1897.

NADEL, George Harrison. Philosophy of history before historicism. In:

(Ed.) Studies in the Philosophy of History: Select essays from History and Theory. New York: Harper \& Row, 1965.

NOIDIER, Charles. Discours Préliminaire. In: MICHAUD, Louis-Gabriel. Biographie universelle ancienne et moderne. v. 1. Paris: Mme. C. Desplace, 1843. Disponível em: <http://www.bnf.fr/>. Acesso em: julho 2014.

OLIVEIRA, Maria da Glória de. Escrever vidas, narrar a história: a biografia como problema historiográfico no Brasil oitocentista. Rio de Janeiro: Editora da Fundação Getúlio Vargas, 2011.

. Crítica, método e escrita da história em João Capistrano de Abreu. Rio de Janeiro: Editora da Fundação Getúlio Vargas; FAPERJ, 2013. 
PALTI, Elias. La nación como problema: los historiadores y la "cuestión nacional”. Buenos Aires: Fondo de Cultura Económica, 2002.

PARECERES SOBRE ADMISSÃO DE SÓCIOS. Revista do IHGB, tomo 29, p. 403-415, 1866.

PORTO ALEGRE, Manuel Araújo. Iconographia Brazileira. Revista do IHGB, Rio de Janeiro, tomo 19, n. 23, p. 349-378, 1856.

RELATÓRIO DO PRIMEIRO SECRETÁRIO O SR. CÔNEGO DR. J. C. FERNANDES PINHEIRO. Revista do IHGB, tomo 27, parte segunda, p. 393$-402,1864$.

REVEL, Jacques. A biografia como problema historiográfico. In: História e historiografia: exercícios críticos. Curitiba: Editora UFPR, 2010. p. 235-248. SANTOS, Evandro. A História geral do Brasil, de Francisco Adolfo de Varnhagen: apontamentos sobre o gênero biográfico na escrita da história Oitocentista. História da Historiografia, Ouro Preto, n. 9, p. 88-105, ago. 2012.

SIMIAND, François. Método histórico e ciência social. Bauru: EDUSC, 2003. SILVA, João Manuel Pereira da. Plutarco Brasileiro. Rio de Janeiro: Laemmert, 1847.

. Os varóes illustres do Brazil durante os tempos coloniaes. 3. ed. Rio de Janeiro: Livraria de B.L. Garnier, 1868. 2 volumes.

Recebido em: 04/07/2014 Aprovado em: 10/10/2014 